\title{
New High-Yield Method for the Production of Activated Carbon Via Hydrothermal Carbonization (HTC) Processing of Carbohydrates
}

\author{
Sanjeev Sharma ${ }^{1 *}$ and Sang-Eun Chun ${ }^{2 *}$ \\ ${ }^{I}$ Duracell, Bethel, Connecticut 06801 \\ ${ }^{2}$ School of Materials Sciences and Engineering, Kyungpook National University, Daegu 41566, South Korea
}

\begin{abstract}
Activated carbons (ACs) are considered important electrode materials for supercapacitors because their large specific surface areas lead to high charging capacities. In the conventional synthesis of ACs, a substantial amount of carbon is lost during carbonization of a precursor. The development of a method to synthesize ACs in high yield would lower their manufacturing cost. Here, we demonstrate the synthesis of high-specific-surface-area $\mathrm{NaOH}-\mathrm{AC}$ from carbon prepared via a hydrothermal carbonization (HTC) route, with a higher yield than that achieved through conventional pyrolysis carbonization. The amorphous carbon was derived from HTC of sugar and subsequently activated at $800^{\circ} \mathrm{C}$ with various $\mathrm{NaOH}$ etchant/C ratios under a $\mathrm{N}_{2}$ atmosphere. The AC prepared at 4:1 NaOH/C exhibited the highest surface area (as high as $\left.2,918 \mathrm{~m}^{2} \mathrm{~g}^{-1}\right)$ and the highest specific capacitance $\left(157 \mathrm{~F} \mathrm{~g}^{-1}\right.$ in $1 \mathrm{M}$ aqueous $\mathrm{Na}_{2} \mathrm{SO}_{4}$ electrolyte solution) among the $\mathrm{NaOH}-\mathrm{AC}$ samples prepared in this work. On the basis of their high specific capacitance, the $\mathrm{NaOH}-\mathrm{ACs}$ prepared from HTC sugar are suitable for use as electrode materials for supercapacitors.
\end{abstract}

Keywords : Carbohydrate, Activated Carbon, Porous Carbon, Hydrothermal Carbonization, $\mathrm{NaOH}$ Activation

Received: 2 April 2019, Accepted : 3 June 2019

\section{Introduction}

Activated carbons (ACs) have found wide applications in multiple fields as a consequence of their unique adsorption properties [1-3]. World demand for activated carbon is forecast to expand $3.5 \%$ per year through 2020 to 970 million pounds [4]. The demand for AC has increased in response to two major environmental regulations implemented by the US Environmental Protection Agency: the Disinfectants and Disinfection Byproducts Rule (DBPR) and the Mercury and Air Toxics Standards (MATS). Both regulations allow utilities and industrial manufacturers in the US to upgrade their coal-fired power plants [4,5]. Powdered AC can be used in coal-fired power plants to adsorb air-phase mercury from flue gas. The

*E-mail address: ssrma15@gmail.com, sangeun@knu.ac.kr DOI: https://doi.org/10.33961/jecst.2019.00059

This is an open-access article distributed under the terms of the Creative Commons Attribution Non-Commercial License (http://creativecommons.org/licenses/by-nc/4.0) which permits unrestricted non-commercial use, distribution, and reproduction in any medium, provided the original work is properly cited. injected AC can reduce the mercury concentration in the flue gas to levels that satisfy emission standards specified in environmental regulations. Another major application of $\mathrm{AC}$ is water purification, where it functions as an adsorbent for the removal of organic and inorganic contaminants [6-9]. In addition, ACs are extensively used in the science and engineering fields because of their reasonably high electronic conductivity, high electrochemical stability, and large specific surface areas. In the construction of heterogeneous catalysts, $\mathrm{AC}$ is utilized as a support for noble metals and as a biocompatible material [10-14]. In recent years, the use of ACs in energy storage applications such as electrodes in electrochemical capacitors and anodes in hybrid storage batteries has been increasing rapidly [6,15-17]. Their broad application in energy storage industry is attributed to their high abundance, and accompanying low cost.

ACs are conventionally manufactured through a two-step process $[1,3,18]$. The first step is the extraction of elemental carbon from an organic raw 


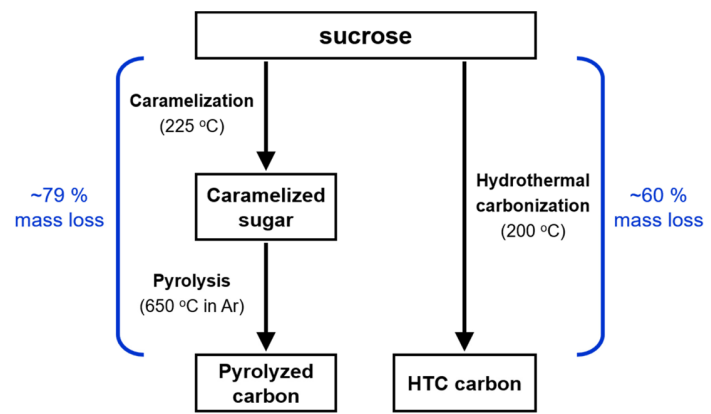

Fig. 1. Comparisons of carbonization yields obtained from thermal pyrolysis and hydrothermal carbonization

material via thermal pyrolysis. During the pyrolysis, the carbon source is first dehydrated at $120^{\circ} \mathrm{C}$ under air and is then heated to at least $450^{\circ} \mathrm{C}$ under an inert atmosphere for several hours until the carbonaceous source is completely dehydrated and rigid carbon rings with $s p^{2}$ bonding form $[1,19,20]$. In the second step, the pyrolyzed carbon is activated using either a chemical agent such as $\mathrm{NaOH}, \mathrm{KOH}, \mathrm{H}_{3} \mathrm{PO}_{4}$, or $\mathrm{ZnCl}_{2}$ under inert conditions or a physical etchant employing steam and $\mathrm{CO}_{2}$ activation $[1,21]$. The thermal pyrolysis of the first step suffers from poor yields: as much as $40-50 \%$ of the constituent carbon contained in the raw material is lost in several cases $[22,23]$ (Fig. 1). This low yield could offset the advantage of low manufacturing cost of ACs [24]. A high-yield process would make ACs more attractive from a cost perspective.

Here, we report the high-yield synthesis of $\mathrm{NaOH}$ ACs from carbonized sucrose via a hydrothermal process. Initially, the precursor sucrose was carbonized via a hydrothermal process in high production yield. This hydrothermal carbonization (HTC) process does not require the laborious caramelization step used in conventional carbonization, where the sugar powder expands in volume approximately 20-50 fold during the caramelization and requires grinding before the subsequent pyrolysis. In our method, the carbon obtained after hydrothermal treatment is subsequently converted into porous activated carbon via $\mathrm{NaOH}$ treatment. We used the produced ACs as an electrode material for an electric double-layer capacitor. The measured specific capacitance value was similar to that of an AC prepared by the conventional two-step activation process.

\section{Experimental}

\subsection{Synthesis}

Sucrose $(>99.5 \%$, Sigma-Aldrich, known as "table sugar") was used as a raw material to prepare the carbon materials for final ACs. The hydrothermal carbonization of the sucrose was carried out in Teflonlined autoclave (100 mL capacity). A sucrose (20 g) was dissolved in $60 \mathrm{~mL}$ of deionized water and transferred to an autoclave. The autoclave was further sealed and heated in an oven at $180^{\circ} \mathrm{C}$ for $16 \mathrm{~h}$. The resultant black carbon chunk was ground into a fine powder using an agate mortar and pestle. To attain a homogeneous particle size, the ground carbon was screened through a $300 \mu \mathrm{m}$ mesh sieve. The homogeneous powdered carbon was used for further activation. For chemical activation, a carbon sample (5 g) was mixed with various amounts of $\mathrm{NaOH}(98 \%$, Alfa Aesar) chemical etching agent (10 g, $15 \mathrm{~g}$, and $20 \mathrm{~g}$ ) in $10 \mathrm{~mL}$ of deionized water. The mixtures were stirred for $1 \mathrm{~h}$ for complete infiltration of the etchant into the carbon and then the final slurry was dried in an oven at $80^{\circ} \mathrm{C}$ for $4 \mathrm{~h}$ to remove excess water. The obtained mixture was then transferred to a horizontal furnace, where it was heat-treated at $800^{\circ} \mathrm{C}$ under a flowing $\mathrm{N}_{2}$ environment $\left(3 \mathrm{ft}^{3} \mathrm{~h}^{-1}\right.$ $=1,416 \mathrm{~cm}^{3} \mathrm{~min}^{-1}$ ) for $2 \mathrm{~h}$. The activation temperature was chosen as $800^{\circ} \mathrm{C}$ because the metallic sodium evolves by the reduction of sodium hydroxide at this temperature [2]. The chemically etched pyrolyzed samples were named according to the gravimetric $\mathrm{NaOH} / \mathrm{C}$ ratio. The sample labels $\mathrm{AC}$ $\mathrm{NaOH}-2, \mathrm{AC}-\mathrm{NaOH}-3$, and $\mathrm{AC}-\mathrm{NaOH}-4$ refer to the AC samples prepared with $\mathrm{NaOH} / \mathrm{C}$ ratios of 2, 3, and 4 , respectively. The obtained AC products were washed with hot deionized water and then with $1 \mathrm{M}$ $\mathrm{HCl}$ solution multiple times to remove remaining alkali from the product. The washed carbon samples were subsequently dried in a vacuum oven at $120^{\circ} \mathrm{C}$ for $24 \mathrm{~h}$. The schematic in Fig. 2 illustrates the synthesis process of the ACs, including the hydrothermal carbonization. The water used in all experiments was double-distilled water (18 M $\Omega$ ).

\subsection{Characterization}

An automated gas adsorption analyzer (NOVA 2000, Quantachrome Instruments) was used to characterize the porous structure of the $\mathrm{NaOH}-\mathrm{AC}$ samples. $\mathrm{N}_{2}$ gas was used as an adsorbent to obtain the 


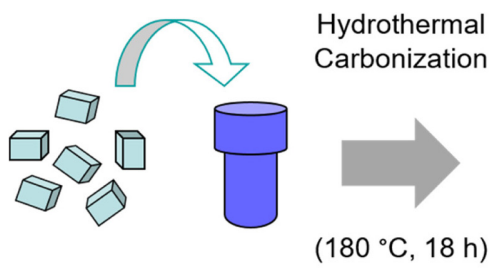

Sugar

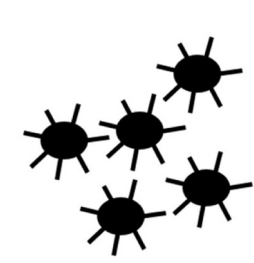

Hydrothermal

Carbonized sugar
$\mathrm{NaOH}$

impregnation

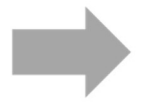

$\left(800^{\circ} \mathrm{C}, 2 \mathrm{~h}, \mathrm{Ar}\right)$

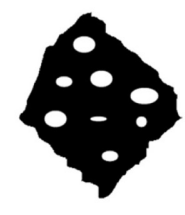

Activated

Carbon

Fig. 2. Schematic of the method used to obtain ACs from sugar via hydrothermal carbonization

adsorption/desorption profiles (isotherms). Prior to the gas-adsorption analysis, the samples were degassed at $300^{\circ} \mathrm{C}$ for $6 \mathrm{~h}$ under vacuum to remove organic contaminants and moisture from their surface.

The electrochemical performance of the ACs was analyzed by cyclic voltammetry (CV) using a multichannel potentiostat (VMP3, Bio-logic). The voltammograms were recorded at a scanning rate of $5 \mathrm{mV} \mathrm{s}^{-1}$ in $1 \mathrm{M} \mathrm{Na}_{2} \mathrm{SO}_{4}$ solution. For the $\mathrm{CV}$ measurements, the powder-type samples were used to prepare composite electrodes composed of an AC sample as the active material, carbon black, and polytetrafluoroethylene (PTFE) as a binder, combined in a 85:10:5 mass ratio. The ingredients used to prepare the composite electrodes were physically mixed using an agate mortar and pestle. The composite electrode materials were deposited onto nickel mesh using a hydraulic press $(70 \mathrm{kN})$. Approximately $3-5 \mathrm{mg}$ of a given composite electrode material was loaded onto a Ni-mesh substrate. The electrochemical measurements were carried out with beaker-type three-electrode cell. The composite electrode was used as the working electrode, and platinum wire and a mercury sulfate electrode were used as the counter and reference electrodes, respectively. The measured potentials were converted to potentials referenced to a normal hydrogen electrode (NHE) as follows [25]:

$$
E(\text { vs. } \mathrm{NHE})=E\left(\text { vs. } \mathrm{Hg} / \mathrm{Hg}_{2} \mathrm{SO}_{4}\right)+0.68 \mathrm{~V}
$$

The specific capacitance was evaluated from the cyclic voltammograms on the basis of the following equation:

$$
C=\frac{\int i_{\mathrm{dis}}(t) d t}{E \times m_{\mathrm{elec}}}
$$

where $i_{\text {dis }}(\mathrm{mA})$ is the discharge current, $E(\mathrm{~V})$ is the
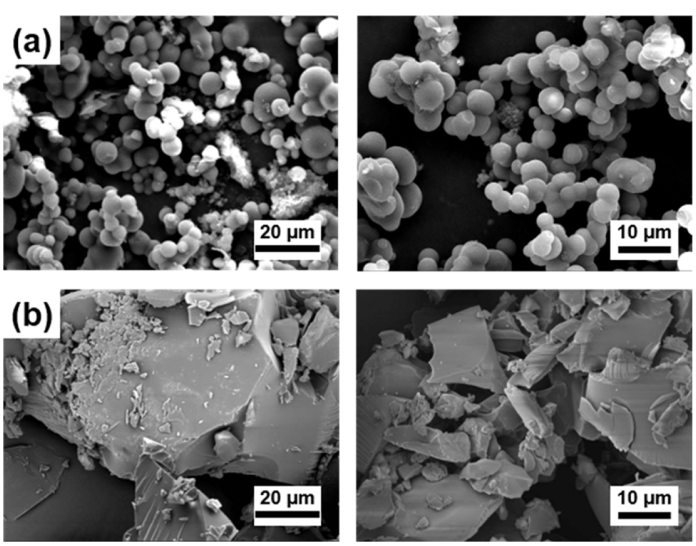

Fig. 3. Scanning electron micrographs of (a) hydrothermally carbonized (HTC) sugar exhibiting a microspherical morphology and (b) carbon powder prepared by conventional thermal pyrolysis

measured voltage window, and $m_{\text {elec }}(\mathrm{g})$ is the total mass of the electrode.

\section{Results and Discussion}

Fig. 3(a) shows illustrative scanning electron micrographs of a HTC sugar sample at low and high magnifications. Compared with the thermally pyrolyzed sugar (Fig. 3(b)), the HTC sugar exhibits a uniform spherical geometry with a diameter on the order of tens of microns. The surface group of the pyrolyzed carbon was characterized by Fourier transform infrared (FTIR) spectroscopy; the corresponding spectrum shows the characteristic $\mathrm{C}=\mathrm{O}$ and $\mathrm{O}-\mathrm{H}$ frequencies at $1780 \mathrm{~cm}^{-1}, 1850 \mathrm{~cm}^{-1}$, and $3600 \mathrm{~cm}^{-1}$, respectively. These features confirm that the surface was hydrophilic [26-28]. This observation was further confirmed on the basis of thermogravimetric analysis (TGA). The TGA curves 
Table 1. Yield comparisons of conventional pyrolysis and hydrothermal carbonization

\begin{tabular}{ccccccc}
\hline \hline Molecular formula & $\begin{array}{c}\mathrm{C} \\
(\%)\end{array}$ & $\begin{array}{c}\mathrm{O} \\
(\%)\end{array}$ & $\begin{array}{c}\mathrm{H} \\
(\%)\end{array}$ & $\begin{array}{c}\text { Theoretical yield } \\
(\%)\end{array}$ & $\begin{array}{c}\text { Pyrolysis yield } \\
(\%)\end{array}$ & $\begin{array}{c}\text { HTC yield } \\
(\%)\end{array}$ \\
\hline $\mathrm{C}_{6} \mathrm{H}_{12} \mathrm{O}_{6}$ & 40.0 & 53.3 & 6.7 & 40 & 21 & 40 \\
\hline
\end{tabular}

of the carbonized sugar samples show a small $3 \%$ weight loss in the region from 150 to $200^{\circ} \mathrm{C}$, which is ascribed to the presence of loosely bonded surface moisture. Another $30 \%$ weight loss in the range 250 $550^{\circ} \mathrm{C}$ is attributed to the dehydration and condensation of various surface hydroxyl groups present on the carbonized solids.

Conventional carbonization of the sucrose precursor includes caramelization and subsequent pyrolysis. The carbon yield of this conventional process is only $20 \%$ of the initial mass. In comparison, the HTC process yields a conversion ratio of almost $100 \%$ based on carbon content (Table 1). HTC works on the principle of dehydration under autogenous pressure at mild temperatures, with the final products having a nanoscale morphology and hydrophilic surface functional groups.

In the chemical activation process, the prepared carbon powders were stirred in the aqueous etching solution for $4 \mathrm{~h}$. This infiltration is a critical pretreatment step because any carbon fraction not sufficiently wetted by the etchant results in a reduced level of activation. The produced carbon powder obtained via HTC exhibits a spherical surface morphology with hydrophilic functional groups, which facilitates homogeneous impregnation by the chemical etchant.

The hydrothermally pyrolyzed sugar was subsequently activated at $800^{\circ} \mathrm{C}$ to create the porous sur- face morphology. The resultant ACs were qualitatively examined by scanning electron microscopy to assess their surface texture and porosity (Fig. 4). The samples have rough surfaces with numerous macrosized pores with various sizes. The samples' surface texture and porosity were quantitatively characterized on the basis of their adsorption/desorption profiles (isotherms) of inert $\mathrm{N}_{2}$ gas (Fig. 5).

Fig. 5 illustrates that all of the ACs exhibit type-I isotherms, which is typical for microporous carbons [29]. All of the isotherms show that a large amount of $\mathrm{N}_{2}$ was adsorbed at low relative pressures $\left(P / P_{0}\right)$, reaching a saturation value at middle and high $P / P_{0}$, which can be explained on the basis of the $\mathrm{N}_{2}$ filling of micropores [29]. The AC-NaOH-4 sample exhibited a higher $\mathrm{N}_{2}$ adsorption volume (saturated adsorbed volume: $900 \mathrm{~cm}^{3} \mathrm{~g}^{-1}$ ) than the other samples. By comparison, samples AC-NaOH-2 and AC$\mathrm{NaOH}-3$ exhibited saturated adsorbed volumes of $150 \mathrm{~cm}^{3} \mathrm{~g}^{-1}$ and $300 \mathrm{~cm}^{3} \mathrm{~g}^{-1}$, respectively. This comparison illustrates that the volume of micropores created in $\mathrm{NaOH}-\mathrm{ACs}$ is directly dependent on the $\mathrm{NaOH} / \mathrm{C}$ ratio.

The differences in microporosity contribute to large differences in the specific surface areas among carbon samples AC-NaOH-2, AC-NaOH-3, and AC$\mathrm{NaOH}-4$. The surface area of the ACs was calculated on the basis of multipoint BET theory at relative
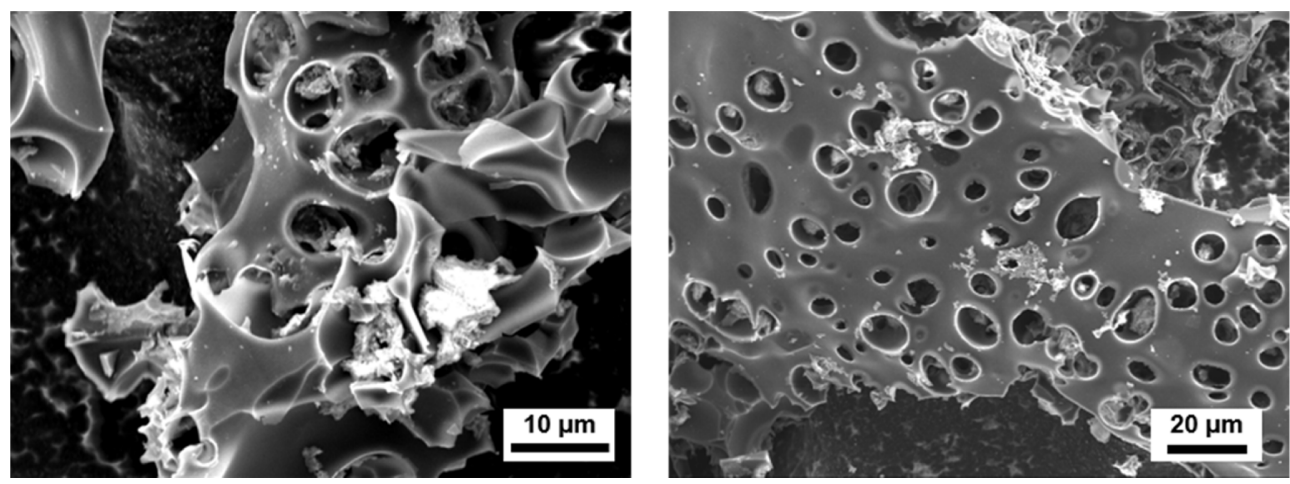

Fig. 4. Scanning electron micrographs of $\mathrm{AC}$ obtained from $\mathrm{NaOH}$ activation of hydrothermally carbonized (HTC) sugar 

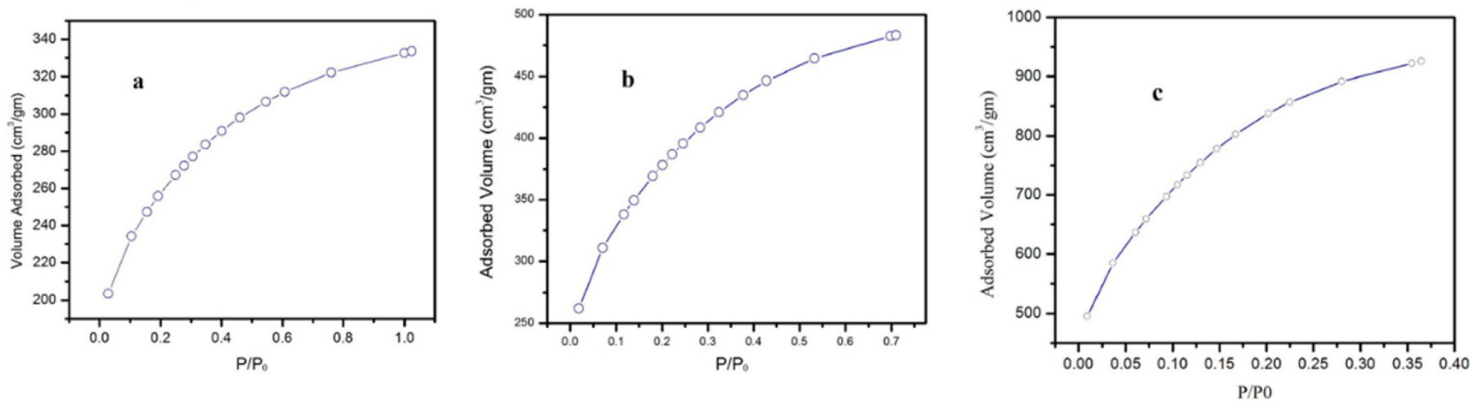

Fig. 5. $\mathrm{N}_{2}$ adsorption graphs of $\mathrm{AC}$ samples (a) AC-NaOH-2, (B) AC-NaOH-3, and (c) AC-NaOH-4

Table 2. Summary of physical and surface characteristics of the carbon

\begin{tabular}{ccccc}
\hline \hline Sample & $\begin{array}{c}\text { BET surface area } \\
\left(\mathrm{m}^{2} \mathrm{~g}^{-1}\right)\end{array}$ & $\begin{array}{c}\text { Total pore volume } \\
\left(\mathrm{cm}^{3} \mathrm{~g}^{-1}\right)\end{array}$ & $\begin{array}{c}\text { Micropore volume ratio } \\
(\%)\end{array}$ & $\begin{array}{c}\text { Mesopore volume ratio } \\
(\%)\end{array}$ \\
\hline AC-NaOH-2 & 1,041 & 0.17 & $45 \%$ & $55 \%$ \\
$\mathrm{AC}-\mathrm{NaOH}-3$ & 1,512 & 0.25 & $59 \%$ & $41 \%$ \\
$\mathrm{AC}-\mathrm{NaOH}-4$ & 2,918 & 0.43 & $65 \%$ & $35 \%$ \\
\hline
\end{tabular}
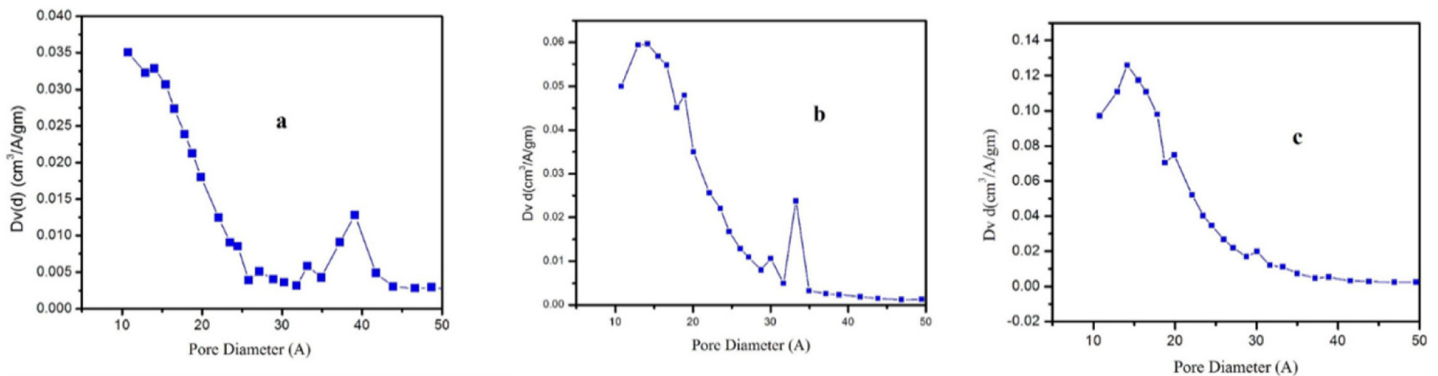

Fig. 6. $\mathrm{BJH}$ pore size distribution plots of activated carbon samples (a) AC-NaOH-2, (B) AC-NaOH-3, and (c) AC-NaOH-4

pressures less than 0.3 [30]. The appropriate range among adsorption points at $0 \leq P / P_{0} \leq 0.3$ was selected to achieve the optimum fitting results until the lowest fitting error was obtained. The estimated specific surface area increased with increasing $\mathrm{NaOH} / \mathrm{C}$ ratio. A large difference was observed in the surface areas of the resultant AC samples. When the $\mathrm{NaOH} / \mathrm{C}$ ratio was increased from 2 to 4 , the specific surface area of the AC increased more than twofold (Table 2).

To analyze the porosity quantitatively, we plotted the pore size distributions of all of the AC samples on the basis of the Barrett-Joyner-Halenda (BJH) method [31](Fig. 6). All of the ACs contain micropores with diameters less than $2 \mathrm{~nm}$, which leads to their large specific surface areas. Samples AC$\mathrm{NaOH}-2$ and $\mathrm{AC}-\mathrm{NaOH}-3$ exhibit the same amount of mesopores in the range of 3-4 $\mathrm{nm}$ in their microporous structures. By contrast, sample AC-NaOH-4 exhibits a unimodal pore distribution in the micropore regime. The micropore volume and mesopore volume ratio were estimated from the pore distribution profile; the results are tabulated in Table 2. The AC sample made from the mixture with lowest $\mathrm{NaOH} / \mathrm{C}$ ratio shows the largest mesopore volume ratio among the prepared $\mathrm{NaOH}-\mathrm{AC}$ samples. Fewer mesopores formed as more $\mathrm{NaOH}$ etchant was added to the mixture. Meanwhile, the micropore volume ratio increased with increasing $\mathrm{NaOH} / \mathrm{C}$ ratio. This result is attributed to the micropore evolution induced 
by $\mathrm{NaOH}$ etching. During the activation with $\mathrm{NaOH}$, pores can be created by the exfoliation of the stacked graphene layers by intercalated sodium metal $[22,23,32]$. The voids between exfoliated graphene layers exposed on the free surface are considered to function as microsized pores. Therefore, when a larger amount of $\mathrm{NaOH}$ was used, as in the case of sample AC-NaOH-4, new micropores developed on the existing micropores and mesopores. Therefore, the amount of mesopores was reduced by the formation of the myriad micropores, leading to the higher micropore ratio. Meanwhile, the specific surface area at higher $\mathrm{NaOH} / \mathrm{C}$ ratios was enhanced because of the evolution of the micropores with a high specific surface area.

When an AC is used as an electrode material in an electrolyte, the electrolyte ions can deploy on the electrode surface under an applied external potential. ACs with a high specific surface area have an important application as electrode materials for supercapacitors. In particular, ACs with a higher specific surface area would have a higher specific capacitance to store electrical charge. To estimate the specific capacitance of the $\mathrm{NaOH}-\mathrm{ACs}$ prepared in the present work, we

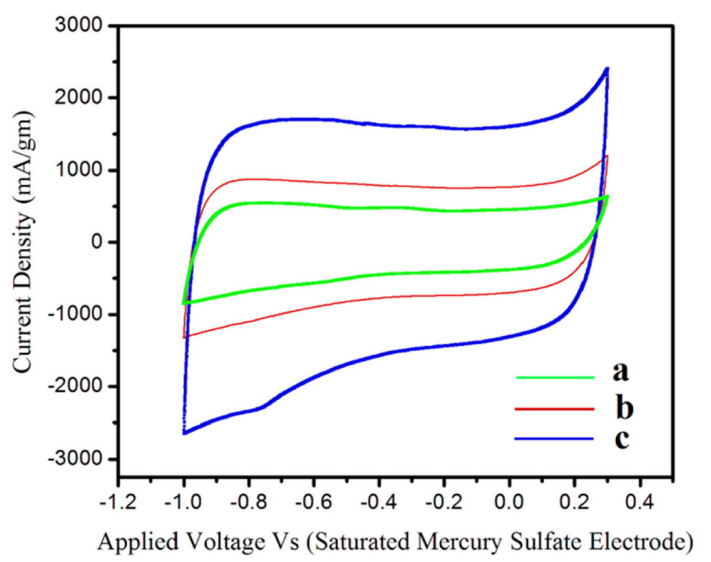

Fig. 7. Cyclic voltammograms of $\mathrm{NaOH}-\mathrm{ACs}$ produced from sugar carbonized via a hydrothermal process: (a) AC$\mathrm{NaOH}-2$, (b) AC-NaOH-3, and (c) AC-NaOH-4 recorded their cyclic voltammograms; the results are shown in Fig. 7. The rectangular shapes of the voltammograms indicate capacitive behavior of the $\mathrm{NaOH}$ electrodes in the $1 \mathrm{M} \mathrm{Na}_{2} \mathrm{SO}_{4}$ electrolyte solution. Among the samples, AC-NaOH-4, prepared with a $\mathrm{NaOH} / \mathrm{C}$ ratio of 4 , exhibits the best performance (specific capacitance : $157 \mathrm{~F} \mathrm{~g}^{-1}$ ), as expected on the basis of its high BET surface area. Table 3 clearly shows that the ACs with higher BET surface areas exhibit higher specific capacitances.

\section{Conclusions}

We developed a process to manufacture ACs from sucrose (carbohydrate) via hydrothermal carbonization and subsequent $\mathrm{NaOH}$ activation in yields as high as $40 \%$, which is close to the theoretical yield. Conventional carbonization includes dehydration of an organic raw material at $\sim 120^{\circ} \mathrm{C}$ and the pyrolysis of the dehydrated precursor at temperatures greater than $400^{\circ} \mathrm{C}$; however, constituent carbon is also lost from the precursor during this process. With our hydrothermal process, the precursor was contained in a closed chamber and heat-treated at $180^{\circ} \mathrm{C}$ under the self-generated pressure. By adopting this hydrothermal pyrolysis, we prepared pyrolyzed sugar powder instead of bulky caramelized sucrose. The laborious mechanical grinding process of caramelized sucrose was avoided, and circumventing the use of bulky caramelized sucrose enabled the use of a smaller reactor for pyrolysis. Furthermore, the loss of the carbon was mostly prevented. In the subsequent activation procedure, $\mathrm{NaOH}$ etchant was used to create a porous structure from the carbonized sugar. Among various investigated $\mathrm{NaOH} / \mathrm{C}$ ratios, a 4:1 ratio led to the best activation performance, as indicated its extremely high specific surface area $\left(2,918 \mathrm{~m} \mathrm{~g}^{-1}\right)$ and total pore volume $\left(43.47 \mathrm{~cm}^{3} \mathrm{~g}^{-1}\right)$. The $\mathrm{NaOH}-\mathrm{AC}$ with a high specific surface area advantageously adsorbed a large amount of electrolyte ions on its surface when tested as a

Table 3. Electrochemical performance of the $\mathrm{NaOH}-\mathrm{ACs}$ prepared under different conditions

\begin{tabular}{cccc}
\hline \hline Sample & $\mathrm{NaOH} / \mathrm{C}$ ratio & BET surface area $\left(\mathrm{m}^{2} \mathrm{~g}^{-1}\right)$ & Specific capacitance $(\mathrm{F} \mathrm{g})$ \\
\hline AC-NaOH-2 & $1: 2$ & 1,041 & 45 \\
AC-NaOH-3 & $1: 3$ & 1,512 & 78 \\
AC-NaOH-4 & $1: 4$ & 2,918 & 157 \\
\hline
\end{tabular}


supercapacitor electrode material. A specific capacitance of $157 \mathrm{~F} \mathrm{~g}^{-1}$ was obtained in $1 \mathrm{M} \mathrm{Na}_{2} \mathrm{SO}_{4}$ electrolyte solution. Compared with conventional pyrolysis and activation, the $\mathrm{NaOH}$ activation of hydrothermally pyrolyzed carbon leads high yields of a carbon electrode material suitable for use in supercapacitor applications.

\section{Acknowledgement}

This research was supported by Kyungpook National University Research Fund, 2016.

\section{References}

[1] H. Marsh, F. Rodriguez-Reinoso. Activated Carbon, Elsevier, 2006.

[2] L.R. Radovic. Chemistry and Physics of Carbon, Vol. 30. New York, CRC Press, 2007.

[3] K. Kinoshita. Carbon: Electrochemical and physicochemical properties. New York, John Wiley and Sons, 1988.

[4] T.F. Group. Activated Carbon: US Industry Study with Forecasts for $2020 \& 2025$, Freedonia, 2006.

[5] Eco-Business, https://www.eco-business.com/press-releases/ us-demand-for-activated-carbon-to-approach-13-billionpounds-in-2017, 2013.

[6] F. Beguin, E. Frackowiak. Carbons for Electrochemical Energy Storage and Conversion Systems, Taylor \& Francis, 2009.

[7] J. Reungoat, B.I. Escher, M. Macova, F.X. Argaud, W. Gernjak, J. Keller. Water Res. 2012, 46(3), 863-872.

[8] T. Otowa, Y. Nojima, T. Miyazaki. Carbon. 1997, 35(9), 1315-1319.

[9] B. Jurado-Sánchez, S. Sattayasamitsathit, W. Gao, L. Santos, Y. Fedorak, V.V. Singh, et al. Small. 2015, 11(4), 499-506.

[10] A.E. Aksoylu, M. Madalena, A. Freitas, M.F.R. Pereira, J.L. Figueiredo. Carbon. 2001, 39(2), 175-185.

[11] H. Jüntgen. Fuel. 1986, 65(10), 1436-1446.
[12] E. Lam, J.H.T. Luong. ACS Catalysis. 2014, 4(10), 3393-3410.

[13] S.R. Sandeman, C.A. Howell, G.J. Phillips, A.W. Lloyd, J.G. Davies, S.V. Mikhalovsky, et al. Biomaterials. 2005, 26(34), 7124-7131.

[14] Y. Fang, D. Gu, Y. Zou, Z. Wu, F. Li, R. Che, et al. Angew. Chem. Int. Ed. 2010, 49(43), 7987-7991.

[15] L.L. Zhang, X.S. Zhao. Chem. Soc. Rev. 2009, 38(9), 2520-2531.

[16] M. Lu, F. Beguin, E. Frackowiak. Supercapacitors: Materials, Systems and Applications, Wiley, 2013.

[17] P. Simon, Y. Gogotsi. Nat. Mater. 2008, 7(11), 845-854.

[18] H. Marsh, D.S. Yan, T.M. O'Grady, A. Wennerberg. Carbon. 1984, 22(6), 603-611.

[19] M. Toda, A. Takagaki, M. Okamura, J.N. Kondo, S. Hayashi, K. Domen, et al. Nature. 2005, 438(7065), 178-178.

[20] C.E. Byrne, D.C. Nagle. Carbon. 1997, 35(2), 259-266.

[21] L.R. Radovic. Chemistry and Physics of Carbon, Vol. 29. New York, CRC Press, 2007.

[22] S.-E. Chun, Y.N. Picard, J.F. Whitacre. J. Electrochem. Soc. 2011, 158(2), A83-A92.

[23] S.-E. Chun, J.F. Whitacre. Electrochim. Acta. 2012, 60, 392-400.

[24] A. Burke. J. Power Sources. 2000, 91(1), 37-50.

[25] A.J. Bard, R. Parsons, J. Jordan. Standard Potentials in Aqueous Solution, Taylor \& Francis, 1985.

[26] P.-C. Hsu, H.-T. Chang. Chem. Commun. 2012, 48(33), 3984-3986.

[27] B. Hu, K. Wang, L. Wu, S.-H. Yu, M. Antonietti, M.-M. Titirici. Advanced Materials. 2010, 22(7), 813-828.

[28] M.-M. Titirici, M. Antonietti. Chem. Soc. Rev. 2010, 39(1), 103-116.

[29] K.S.W. Sing, D.H. Everett, R.A.W. Haul, L. Moscou, R.A. Pierotti, J. Rouquerol, et al. Pure Appl. Chem. 1985, 57(4), 603-619.

[30] S. Brunauer, P.H. Emmett, E. Teller. Journal of the American Chemical Society. 1938, 60(2), 309-319.

[31] E.P. Barrett, L.G. Joyner, P.P. Halenda. Journal of the American Chemical Society. 1951, 73(1), 373-380.

[32] S.-E. Chun, J.F. Whitacre. J. Power Sources. 2013, 240, 306-313. 